\title{
Vivências de violência obstétrica experimentadas por parturientes
}

\section{Experiences of obstetric violence experienced by parturients}

Maria do Socorro Santos de Oliveira ${ }^{1}$, Victor Sebastião Carvalho da Rocha ${ }^{1}$, Teresa Maria Siqueira Nascimento Arrais ${ }^{1}$

Sabrina Martins Alves ${ }^{1}$, Amanda de Andrade Marques ${ }^{2}$, Dayanne Rakelly de Oliveira ${ }^{3}$, Milana Drumond Ramos Santana ${ }^{4}$

'Departamento em Enfermagem, Faculdade de Juazeiro do Norte (FJN) - Juazeiro do Norte (CE), Brasil.

${ }^{2}$ Curso Nutrição, FJN - (CE), Brasil.

${ }^{3}$ Departamento em enfermagem, Universidade Regional do Cariri (URCA) - Crato, (CE), Brasil.

${ }^{4}$ FJN - Juazeiro do Norte (CE), Brasil.

DOI: https://dx.doi.org/10.7322/abcshs.v44i2.1188

\section{RESUMO}

Introdução: A violência apresenta várias faces e, nesse contexto, pode ocorrer no cenário das instituições de saúde a violência obstétrica, que pode ser definida por qualquer ato ou conduta que venha a causar morte, sofrimento seja de ordem sexual, física ou psicológica à mulher, que pode ocorrer em instituições públicas ou privadas. Objetivo: Analisar as experiências de trabalho de parto e parto de mulheres que sofreram violência obstétrica.

Método: Estudo descritivo, transversal, com abordagem qualitativa. Desenvolveu-se em Unidades Básicas de Saúde (UBS) do município de Juazeiro do Norte, região Sul do Ceará, Brasil. Foram convidadas a participar do estudo mulheres que sofreram violência obstétrica no referido município e que estivessem cadastradas em UBS desta mesma cidade. Os critérios de inclusão, mulheres que foram mães em um período de até seis meses e sofreram violência obstétrica. Para a coleta de dados, realizou-se uma entrevista semiestruturada, utilizandose do critério de saturação dos dados. Para a interpretação dos resultados foi utilizada a técnica de análise de conteúdo. Resultados: $O$ estudo evidenciou que as mulheres sentiram medo, insegurança e ficaram de fato assustadas em estar no ambiente da maternidade. Revelou que à assistência precisa ser modificada, com maior clareza, até para os profissionais, sobre a violência obstétrica. Notou-se que as mulheres não souberam identificar ao certo o que é violência obstétrica e de que forma sofreu essa violência. E por fim, percebeu-se que essa violência afeta no vinculo do binômio mãe-filho. Conclusão: É preciso uma assistência humanizada e qualificada a estas mulheres neste momento tão delicado e importante de suas vidas.

Palavras-chave: parto; trabalho de parto; exposição à violência.

\begin{abstract}
Introduction: Violence has many faces and, in this context, may occur in the setting of health institutions obstetric violence, act or conduct based on gender, causing death, damage or suffering of a physical, sexual or psychological nature to women, both in the public sphere and in private. Objective: To analyze the labor and delivery experiences of women who suffered obstetric violence. Methods: Descriptive, cross-sectional study with qualitative approach, developed at Primary Health Centers (UBS) of the municipality of Juazeiro do Norte, southern region of Ceará, Brazil. Women registered in UBS of this city who suffered obstetric violence were invited to participate in the study. The inclusion criteria were women who were mothers in a period of up to six months and who suffered obstetric violence. Data collection used a semi-structured interview, using the data saturation criterion. The interpretation of the results used the content analysis technique. Results: The study showed that these women felt fear, insecurity and were actually scared to be in the maternity setting. It revealed the need for care change, and the need for more clarity, even for professionals, on obstetric violence. These women do not know for sure what obstetric violence is and the way they suffered this violence. Finally, the study showed that this violence affects the bond of the mother-child binomial. Conclusion: It is necessary to provide humanized and qualified assistance to these women at this very delicate and important time in their lives.
\end{abstract}

Keywords: parturition; labor obstetric; exposure to violence.

Recebido em: 09/08/2018

Revisado em: 15/11/2018

Aprovado em: 18/01/2019

Autor para correspondência: Maria do Socorro Santos de Oliveira - Faculdade de Juazeiro do Norte - Rua São Francisco, 1224 - Bairro São Miguel CEP: 63010-210 Juazeiro do Norte (CE), Brasil - E-mail: maria.mariadosocorro.santos@hotmail.com

Conflito de interesses: nada a declarar. 


\section{INTRODUÇÃO}

Sabe-se que o parto e o nascimento são momentos transformadores na vida das mulheres e seus familiares, no entanto a forma de parir modificou-se muito até os dias atuais, devido às grandes formas tecnológicas e a necessidade de utilizar um tempo reduzido para realização de cada parto ${ }^{1}$.

Contudo, o parto somente começou a ter assistência, a partir do momento que as próprias mulheres começaram a se ajudar neste processo, por meio da ajuda dos seus familiares e das parteiras, mulheres que foram acumulando experiências passando de geração para geração, fazendo-se presente neste momento tão importante e esperado de suas vidas ${ }^{2}$.

Estudos mostram que os partos passaram a ser realizados em ambiente hospitalar, abandonando aquele padrão do nascimento em ambiente domiciliar com a presença de familiares passando a ser um modelo mais preocupado, apenas com o processo fisiológico da mulher, relacionado com a expulsão do concepto, não se preocupando com as necessidades da mãe e do recém-nascido ${ }^{3}$.

Desta forma, a mulher e seu bebê passaram a ter uma assistência com maior número de práticas intervencionistas, sem que nada fosse esclarecido ou consentido. A partir deste momento, o parto passou a ser vivenciado com intenso sofrimento físico e moral, o que acarretou em tensão, medo e muita dor, vivenciada pelas parturientes ${ }^{4}$.

Segundo um Inquérito Nacional sobre Parto e Nascimento, realizado entre os anos de 2011 e 2012, revela que a maioria das mulheres teve seus filhos através de partos cirúrgicos, equivalendo a um percentual de $52 \%$ no setor publico e $88 \%$ no privado, e o que torna esse dado ainda mais alarmante é que as maiorias destas cesarianas ocorreram sem justificativas clínicas ${ }^{5}$.

Contudo, a violência se caracteriza por diversas formas e, nesse contexto, tem-se um tipo de violência, que ocorre nas instituições de saúde, a violência obstétrica, que se tornou cada vez mais comum. Sabe-se ainda que as mulheres, ao longo da história, são conhecidas como as mais prováveis vítimas de violência ${ }^{6}$.

Contudo, a violência obstétrica pode ser cometida por qualquer tipo de profissional que cause negligência na assistência, discriminação social, violências verbais, físicas e psicológicas, como também o uso de tecnologias e procedimentos inadequados durante o ciclo gravídico-puerperal sem ser consentido e/ou informado a parturiente/gestante, ferindo os princípios dos direitos individuais da mulher. Visto que, estes atos, podem contribuir para complicações ou efeitos indesejáveis ao binômio mãe-filho ${ }^{7}$.

Deste modo, ao direcionar os cuidados obstétricos antes, durante e após o parto, deve-se reconhecer que toda mulher tem o seu direito legal de receber tratamento sem danos e maus-tratos, obter informações, consentimento esclarecido com possibilidades de recusas com garantias de respeito às suas escolhas preferenciais, incluindo acompanhante no decorrer da internação na unidade obstétrica, tendo garantias de privacidade e sigilo, deve ser tratada com dignidade e respeito, o tratamento recebido deve ser igual para todas sem a discriminação e com atenção equitativa, deve receber os cuidados profissionais com acesso ao mais alto nível possível de saúde com liberdade, autonomia, autodeterminação e não-coerção ${ }^{8}$.

Diante desse contexto, indaga-se: quais foram às vivências que as parturientes experimentaram em relação à violência obstétrica?

Percebe-se então, a necessidade de ampliar os conhecimentos sobre a assistência prestada às mulheres em trabalho de parto $\mathrm{e}$ parto, pois a mulher detém sobre si informações, emoções, sentimentos, percepções e direitos no gestar e parir.

Portanto, é necessário o respeito a individualidade, a privacidade e a autonomia de cada mulher, as quais são condições altamente necessárias para que ocorra o parto humanizado e sem traumas que possa acompanhar fora da instituição.

Desta forma, constituiu-se como objetivo desse estudo analisar as vivências de violência obstétrica experimentadas por parturientes.

\section{MÉTODO}

Trata-se de um estudo qualitativo. A pesquisa foi desenvolvida na Unidade Básica de Saúde (UBS) no município de Juazeiro do Norte, região sul do Ceará, Brasil, com uma população de 266.022 habitantes ${ }^{9}$. A coleta de dados foi realizada no período de janeiro a março de 2017.

A população-alvo foi composta inicialmente por 28 mulheres entrevistadas, destas, oito foram excluídas por não atenderem aos seguintes critérios de inclusão e exclusão: estar cadastrada na UBS do referido município, ser mãe em um período mínimo de seis meses e ter sofrido violência obstétrica, no entanto excluiu-se do estudo mulheres menores de 18 anos de idade. As cinco participantes que restaram foram excluídas por saturação dos dados.

Inicialmente solicitou-se à instituição lócus permissão para realização da coleta de dados. Após autorização concedida, realizou-se levantamento da lotação das mulheres cadastradas na unidade de saúde. Desta forma o pesquisador se deslocou nos dois turnos (manhã e tarde) ao qual a unidade estava em funcionamento, objetivando entrar em contato com as mulheres, avaliar os critérios de inclusão e convidar para participar da pesquisa. Após contato inicial e autorização para participar da pesquisa, agendou-se as coletas. Das 28 mulheres contatadas, nove não foram incluídas, pois não havia sofrido violência obstétrica ou não era mãe no período mínimo exigido. Assim, das 19 mulheres realizou-se coleta com 15, visto que neste momento identificou-se a saturação dos discursos, ou seja, a repetição dos dados apresentados.

Para instrumento de coleta de dados foi realizado uma entrevista semiestruturada. O investigador possuía em mãos uma lista de questões ou tópicos para serem preenchidos ou respondidos, como se fosse um guia. Esse guia norteou a forma para a comunicação entre o pesquisador e a mulher. A aplicação do 
instrumento de pesquisa aconteceu após explicação de todos os procedimentos da pesquisa e demais informações referentes ao tema estudado, e a mesma ocorreu de forma individual e numa sala da unidade utilizada para as palestras e reuniões, sala arejada e com boa iluminação, garantindo-se a privacidade no fornecimento de informações. Ainda, objetivando o sigilo das informações, os profissionais entrevistados foram nomeados com nomes relativos à M1 à M15.

Para a organização dos resultados foi utilizada a técnica de análise de conteúdo ${ }^{10}$, que em por objetivo descrever o conteúdo da mensagem em três fases: 1) Pré-análise; 2) Exploração do material; 3) Tratamento dos resultados, inferência e interpretação.

Após a organização emergiram as seguintes categorias: Categoria 1) O momento da internação; 2) Assistência prestada às parturientes; 3) As diversas faces da violência obstétrica: identificação e sentimentos; 4) Consequências da violência obstétrica ao binômio mãe e filho.

O estudo foi aprovado pelo Comitê de Ética em pesquisa da Faculdade de Juazeiro do Norte, em 31/10/2016, com o número: 1.802.268. Respeitou as normas nacionais e internacionais regulamentadoras de pesquisas envolvendo seres humanos.

Tabela 1: Caracterização do perfil das participantes.

\begin{tabular}{|l|l|}
\hline Variável & $\mathbf{n}$ \\
\hline Idade (anos) & 5 \\
\hline 17 a 20 & 6 \\
\hline 21 a 25 & 2 \\
\hline 26 a 30 & 2 \\
\hline 30 a 38 & \\
\hline Estado civil & 8 \\
\hline Solteira & 7 \\
\hline Casada & \\
\hline Escolaridade & 2 \\
\hline Frequenta a escola & 1 \\
\hline Ensino fundamental & 6 \\
\hline Ensino médio incompleto & 4 \\
\hline Ensino médio completo & 2 \\
\hline Ensino superior & \\
\hline Raça/cor & 7 \\
\hline Parda & 5 \\
\hline Negra & 4 \\
\hline Branca & 4 \\
\hline Profissão/ocupação & 1 \\
\hline Desempregada & 2 \\
\hline Professora & 4 \\
\hline Auxiliar de professor & \\
\hline Estudante & \\
\hline & \\
\hline
\end{tabular}

\section{RESULTADOS}

A Tabela 1 mostra as características do perfil das participantes. Após traçar o perfil das participantes, foi necessário caracterizar essas mulheres quanto ao tipo de parto e local do parto. Assim, a Tabela 2 mostra as características das participantes quanto ao tipo e local do parto.

\section{Categoria 1: 0 momento da internação}

São de suma importância que essas mulheres expressem a sua opinião, experiências e sentimentos sobre essa internação e o momento do parto. Contudo, evidenciou-se que essas mulheres sentiram medo, insegurança e ficaram de fato assustadas em estar naquele ambiente, como mostram os relatos abaixo:

"Eu me senti bem durante a internação, mas logo depois do parto eu tive que fazer uma cirurgia por conta de uma hemorragia. Eles não me explicaram nada do que estava acontecendo. Fiquei muito assustada naquele ambiente. Mas pelo menos deixaram a minha mãe entrar." (M2)

“...eu fiquei deitada enquanto sentia as contrações e as vezes eu não conseguia colocar força lá embaixo sabe? Mas a enfermeira disse que eu tinha que colocar e aguentar já que eu tinha escolhido ter bebê... eu fiquei muito desconfortável, me senti insegura de minha filha não nascer por conta que eu não estava colocando força, mas no fim fizeram a cesárea... minha cunhada me acompanhou."(M1)

"Eu me senti acolhida, mas eu passei o dia todinho pra ter bebê, acho que eles esperam a pessoa ter trabalho de parto pra depois poder ir pra sala de cirurgia... à noite quando eu já tava tendo hemorragia me levaram pra sala de parto, fiquei com medo do que podia acontecer, mas fiquei deitada o tempo todo, minha mãe ficou comigo, eu estava muito desconfortável" (M3)

"Só posso dizer que me senti muito humilhada... nunca mais quero passar por isso novamente." (M15)

\section{Categoria 2: Assistência prestada às parturientes}

Os relatos abaixo mostraram que essa assistência precisa ser modificada, e que é necessário maior clareza, para as mulheres, sobre a violência obstétrica.

Tabela 2: Caracterização quanto ao tipo de parto e local de parto.

\begin{tabular}{|l|c|}
\hline Variável & n \\
\hline Tipo de parto & 11 \\
\hline $\begin{array}{l}\text { Cesárea } \\
\text { Parto normal }\end{array}$ & 4 \\
\hline $\begin{array}{l}\text { Local do parto } \\
\text { de referência da rede pública }\end{array}$ & 13 \\
\hline Hospital privado & 2 \\
\hline
\end{tabular}


"Eu tenho problema de coração e na minha ficha tinha dizendo que era pra eu fazer a cesariana, mas quando eu cheguei na sala de cirurgia a doutora queria induzir o meu parto, depois veio outro médico e disse que tava indisposto pra fazer a cesariana, dai eles saíram e eu fiquei lá sentindo dor e só iam na hora de fazer o exame de toque..." (M4)

"Cheguei no hospital a tarde e só me atenderam no outro dia de manhã. Eu não tinha passagem pra ter parto normal, mas mesmo assim me deixaram lá sentindo muita dor e eles não fizeram nada... eu gritava de dor e a enfermeira disse: mulher ajuda aí, quanto mais você grita mais eles vão demorar a fazer o exame!"(M7)

“Tinha uns estudantes lá, ai um doutor lá disse que eles tinham que aprender pra futuramente atender a gente, aí eles ficavam só indo fazer o exame de toque, tinha uns que não dava pra sentir tanta dor, mas tinha outros que me dava vontade de gritar, mas não gritava com medo deles brigarem..." (M12)

"Fizeram o exame de toque várias vezes, sentia muita dor, eu falava que estava doendo, mas aí eles não faziam nada, eles não me explicaram porque estava fazendo tanto esse exame..." (M9)

"Eu só soube que tava indo fazer a cirurgia quando eu cheguei lá, eles disseram que tava tendo uma hemorragia e precisava ir logo pra sala de cirurgia... quando eu cheguei lá eu tava com muito calafrio, ai eles me amarraram, os braços e as pernas, acho que pra não atrapalhar na hora da cirurgia né?" (M5)

\section{Categoria 3: As diversas faces da violência obstétrica: identificação e sentimentos}

Os relatos evidenciaram que essas mulheres não sabem identificar o que é a violência obstétrica e de que forma sofreu essa violência. Elas evidenciam somente que foi uma experiência dolorosa e cheia de cicatrizes que vai além de marcar o corpo, marcou de fato a alma.

“Eu não sei te dizer o que é violência obstétrica." (M9)

"Eu não posso te dizer nada, não sei o que é essa violência." (M2)

"O que eu sei é que passei por uma situação que não gostei no meu parto, mas te dizer o que me violentou ou o que é essa violência, eu não sei."(M12)

"Eu acho que essa violência é uma forma de mal tratar a gente quando vamos ter bebê, acho que sei lá, o que eu passei muitas passam."(M10)

"Esse tema que você tá falando aqui não é muito falado na televisão não, acho que seria importante ser mais falado pra gente entender melhor o que seria isso."(M11)

\section{Categoria 4: Consequências da violência obstétrica ao vínculo mãe-recém-nascido}

Diante dos relatos, ficou claro que essa violência afeta aos binômios mãe e filho, já que a mãe passa por situações devastadoras afetando o vínculo entre ela e seu filho.

"Eu fiquei com depressão pós-parto até uns 4 meses, confesso que tratei mal o meu filho por conta disso, mas nunca cheguei a bater nele ou algo do tipo, só era um pouco indiferente a ele."(M4)

"Ele ficou bem, mas nunca mais quero ter filhos novamente, e pode influenciar porque se depender de mim ele nunca vai ter irmão." (M6)

"Eu fiquei um pouco distante dele assim que ele nasceu, eu chorava muito e acho que isso afetou até no meu leite."(M7)

\section{DISCUSSÃO}

Hoje em dia, a moderna obstetrícia hospitalar, compõe-se de técnicas e normas institucionais que reforçam a ideia de que a mulher não possui mais capacidade de parir como antes, ou seja, sem aquele modelo de parturição em casa com a presença de familiares. Esta concepção reforça ainda mais a ideologia de que no hospital estará protegendo a mulher e o seu filho, pela tecnologia ali oferecida ${ }^{2}$.

Todavia, alguns profissionais acreditam ainda que essa tecnologia é normal e faz parte da rotina. No entanto, as mulheres, por terem que seguir esse modelo muitas vezes imposto pela própria instituição, se torna, no momento de parturição, mais susceptíveis a sentirem medo, dor e opressão por não poder emitir opinião ou por estarem vivenciando um período extremamente especial de suas vidas: o nascimento de seu bebêt $\hat{}^{6}$

Contudo, sabe-se que a mulher possui direitos no momento da parturição como sentar, deambular e deitar durante o trabalho de parto, e que sejam amparadas e encorajadas na sua escolha de parir, salvo algumas regras onde a parturiente deve manter-se deitada no leito ${ }^{8}$.

Por conseguinte, o processo de hospitalização pode acabar exigindo da mulher e seus familiares, adaptações ao ambiente que estão inseridos, o hospital, e aos profissionais que atuam naquele local. Essas adaptações e mudanças podem provocar além de insegurança e medo, falta de conforto e comodidade para vivenciar um momento tão especial em suas vidas. E, um atendimento inadequado, pode tornar o cuidado fragilizado, o que acarreta em implicações durante o processo de parturição ${ }^{11}$.

Estes dados discutidos corroboram com os achados da categoria um do presente estudo ao ficar claro que as mulheres dos discursos sentiram medo, insegurança e ficaram de fato assustadas em estar naquele ambiente. 
Portanto, Ferreira et al. ${ }^{3}$ acreditam ser necessário o reconhecimento do parto como um processo de envolvimento com o cuidado do outro, e desse modo seja compreendido e respeitada a sua autonomia, suas escolhas, princípios, desejos e afetividades. Como também é necessário que a parturiente sinta-se aconchegada por meio de uma palavra, de um toque e de um sentimento; e que a humanização se mostre de forma mais efetiva, mais complexa e mais presente.

Para o profissional de saúde que atua no processo do trabalho de parto é imprescindível que o significado do cuidado e sua implicação para ser cuidado estejam claros no momento de desenvolver suas habilidades, os valores pessoais, a sensibilidade, além do mais estabelecer uma relação de auxílio e confiança, que permite ao outro ensinar/aprender a ser cuidado ${ }^{11}$.

No entanto, no que se refere à categoria dois do presente estudo, diante dos discursos das mulheres, ficou claro que é necessário à melhora na assistência prestada a elas. Estes resultados estão de acordo com um estudo que foi realizado para averiguar a percepção dos profissionais de saúde que atuam no cuidado ao parto, onde se concluiu que a maioria dos profissionais tem nitidez sobre os aspectos fundamentais da humanização, entretanto, existe uma oposição à mudança das práticas assistenciais ${ }^{12}$.

No que diz respeito à violência obstétrica, percebeu-se nos discursos a desinformação das mulheres à cerca do seu conceito. No entanto, para transformar esse cenário é indispensável ações de educação permanente em saúde para os profissionais da área, com o objetivo de ampliar a compreensão da humanização do nascimento, levando educação e informação a essas mulheres tornando-as participativas do processo de cuidar e da educação permanente ${ }^{12}$.

Sabe-se também que estudos sobre a satisfação da mulher com a experiência de dar à luz são escassos. Em contrapartida, foi comprovado pelo Teste da Violência obstétrica, respondido por quase duas mil mulheres nos meses de março e abril de 2012, em que metade delas se disse insatisfeita com a qualidade do cuidado médico e hospitalar recebido para o nascimento de um filho ${ }^{13}$.

Contudo, a violência vem ganhando caráter endêmico em todo o mundo, estando presente na vida de milhões de pessoas, famílias e comunidades cotidianamente. No entanto, a violência contra a mulher está em larga expansão ao qual apresenta-se em distintas formas e expressões que tem sido extremamente presente e muitas vezes não identificada, como a violência obstétrica ${ }^{14}$.

A Organização Mundial de Saúde (OMS) define violência como a imposição de um grau significativo de dor e sofrimento evitáveis. Já violência contra a mulher, abrange fisicamente, sexual e/ou psicológica e, inclui qualquer ato ou conduta baseada no gênero, que venha causar morte, dano ou sofrimento, causado em instituições privadas ou públicas ${ }^{6}$.

Desta forma, ao direcionar os cuidados obstétricos durante o momento de parturição, é necessário conhecer os direitos legais de todas as mulheres que devem receber tratamento totalmente livre de danos e maus-tratos, obter informações, consentimento esclarecido com possibilidades de recusa tendo garantia de respeito às suas escolhas e preferências, acompanhante durante todo o processo, privacidade e sigilo, ser tratada com dignidade e respeitosamente, o tratamento deve ser com igualdade, sem discriminações e com atenção equitativa, ter os cuidados profissionais com acesso ao mais alto nível possível de saúde com liberdade, autonomia, autodeterminação e não-coerção ${ }^{7}$.

Contudo, a categoria três mostra o quanto à mulher possui uma experiência dolorosa e cheia de cicatrizes durante o parto. Para tanto, o Ministério da saúde, como estratégia ao enfrentamento desta realidade, desenvolveu o Programa Maternidade Segura que tem como objetivo respeitar a dignidade humana, os sentimentos, as escolhas e preferências de todas as mulheres, sendo, portanto, mais do que a prevenção de mortes e morbidades como também, o desenvolvimento de um olhar holístico sobre as mulheres ${ }^{6}$.

Já no que diz respeito ao vínculo mãe-recém-nascido, vários autores vêm pesquisando há décadas a formação desse vínculo desde gestação até os primeiros anos de vida. Estas pesquisas vêm se tornando importante pelo fato de tentar compreender como se estabelece essa relação e que consequências elas podem trazer ao binômio mãe-filho. No entanto, deve-se reforçar que o desenvolvimento social, emocional, físico e cognitivo de recém-nascidos e crianças e os modelos de relações que estabelecerão ao longo da vida estão intimamente ligadas ao vínculo com a mãe $\mathrm{e}^{15}$.

Todavia, a mãe vem construindo a sua maternidade durante meses em todo período gestacional, no entanto a formação do vínculo mãe-recém-nascido, começa a se concretizar no momento do parto já que ali ela está suprindo todas as suas expectativas e fantasias sobre seus filhos, está reorganizando-se emocionalmente, como também está estabelecendo o seu primeiro contato e olhar com o seu filho ${ }^{16}$.

Diante disto e todos os discursos relatados por estas mulheres, a categoria quatro deixa claro que além do sofrimento, medo, dor, falta de privacidade e conhecimento a cerca da violência obstétrica, estas mulheres ainda são afetadas, a partir das suas experiências ruins, na criação do vínculo com os seus filhos.

Desta forma, faz-se necessário que essas mulheres tenham uma melhor assistência neste momento tão peculiar de suas vidas. No entanto, a humanização da assistência ainda configura-se como um grande desafio para os profissionais, às instituições de saúde e para a sociedade. Quando se tem humanização nos serviços de saúde, têm-se os direitos das pacientes respeitados, resgatando o papel de protagonista da sua vida e do seu parto ${ }^{17}$.

Em conclusão, a violência obstétrica ainda é um tema pouco falado entre as usuárias do serviço público de saúde, no entanto este estudo pode expressar as suas vozes, cheias de medo e inseguranças, mas que pode alcançar tantas outras que passam diariamente por experiências semelhantes. Mostrou ainda que a experiência 
do parto tem sido vivenciada com dor, falta de privacidade e autonomia, onde a mulher deixa de ser a sua própria protagonista para experimentar momentos de angústias e intenso sofrimento.

Evidenciou-se ainda o quanto essas experiências no trabalho de parto e nascimento podem afetar o vínculo mãe-recém-nascido, levando consequências desde a vida social da criança até desenvolvimento cognitivo.

Então, isto determina mais uma vez que é preciso uma assistência humanizada e qualificada a estas mulheres neste momento tão delicado e importante de suas vidas.

\section{REFERÊNCIAS}

1. Silva ALS, Nascimento ER, Coelho EAC. Práticas de enfermeiras para promoção da dignificação, participação e autonomia de mulheres no parto normal. Esc Anna Nery. 2015;19(3):424-31. http://dx.doi.org/10.5935/1414-8145.20150056

2. Gonçalves R, Aguiar CA, Merighi MAB, Jesus MCP. Vivenciando o cuidado no contexto de uma casa de parto: o olhar das usuárias. Rev Esc Enferm USP. 2011;45(1):62-70. http://dx.doi.org/10.1590/S0080-62342011000100009

3. Ferreira KM, Viana LVM, Mesquita MASB. Humanização do parto normal: uma revisão de literatura. Rev Saúde Foco. 2014;1(2):134-48

4. Moura FMJSP, Crizostomo CD, Nery IS, Mendonça RCM, Araújo OD, Rocha SS. A humanização e a assistência de enfermagem ao parto normal. Rev Bras Enferm. 2007;60(4):452-65. http://dx.doi.org/10.1590/S0034-71672007000400018

5. Leal MC, Gama SGN. Inquérito Nacional sobre parto e nascimento: Nascer no Brasil. Sumario executivo temático nascer no Brasil. Ministério da Saúde, 2012.

6. Wolff LR, Waldow VR. Violência Consentida: mulheres em trabalho de parto e parto. Saúde Soc. 2008;17(3):138-51 http://dx.doi.org/10.1590/S0104-12902008000300014

7. Andrade PON, Silva JQP, Diniz CMMD, Caminha MFCC. Fatores associados à violência obstétrica na assistência ao parto vaginal em uma maternidade de alta complexidade em Recife, Pernambuco. Rev Bras Saúde Mater Infant. 2016;16(1):29-37. http://dx.doi.org/10.1590/1806-93042016000100004

8. Viana DP, Alves VH, Penna LHG, Pereira AV, Branco MBLR, Silva LA. A peregrinação no período reprodutivo: uma violência no campo obstétrico. Esc Anna Nery. 2015;19(4):614-20. http://dx.doi.org/10.5935/1414-8145.20150082

9. Instituto Brasileiro de Geografia e Estatística (IBGE). Estimativas de população, 2015. Disponível em: http://www.ibge.gov.br/ home/estatistica/populacao/ estimativa2015/estimativa dou.shtm/. Acesso em: 10 ago. 2018.

10. Bardin L. Análise de conteúdo. São Paulo: Edições 70; 2011.

11. Pieszak GM, Terra MG, Neves ET, Pimenta LF, Padoin SMM, Ressel LB. Percepção dos profissionais de enfermagem acerca do cuidar em centro obstétrico. Rev Rene. 2013;14(3):568-78. http://dx.doi.org/10.15253/rev\%20rene.v14i3.3435

12. Weidle WG, Medeiros CRG, Grave MTQ, Dal Bosco SM. Escolha da via de parto pela mulher: autonomia ou indução? Cad Saúde Coletiva. 2014;22(1):46-5. http://dx.doi.org/10.1590/1414-462X201400010008

13. Silva MG, Marcelino MC, Rodrigues LSP, Toro RC, Shimo AKK. Violência obstétrica na visão de enfermeiras obstetras. Rev Rene. 2014;15(4):720-8.

http://dx.doi.org/10.15253/rev\%20rene.v15i4.1121

14. Faneite J, Feo A, Merlo JT. Grado de conocimiento de violencia obstétrica por el personal de salud. Rev Obstet Ginecol Venez. 2012;72(1):4-12.

15. Salgado HO, Niy DY, Diniz CSG. Meio grogue e com as mãos amarradas: o primeiro contato com o recém-nascido segundo mulheres que passaram por uma cesárea indesejada. J Hum Growth Dev. 2013;23(2):190-97.

https://doi.org/10.7322/jhgd.61298

16. Pereira PK, Lovisi GM, Lima LA, Legay LF. Complicações obstétricas, eventos estressantes, violência e depressão durante a gravidez em adolescentes atendidas em unidade básica de saúde. Rev Psiquiatr Clín. 2010;37(5):216-22. http://dx.doi.org/10.1590/S0101-60832010000500006

17. Frello AT, Carraro TE, Bernardi MC. Cuidado e conforto no parto: estudos na enfermagem brasileira. Rev Baiana Enfermagem. 2011;25(2):173-84.

http://dx.doi.org/10.18471/rbe.v25i2.5093 